\title{
Quantitative Evaluation for the Threat Degree of a Thermal Reservoir to Deep Coal Mining
}

\author{
Yun Chen $\mathbb{D}$, ${ }^{1}$ Xinyi Wang $\mathbb{D}^{1,2,3}$ Yanqi Zhao ${ }^{1},{ }^{1}$ Haolin Shi $\mathbb{D},{ }^{1}$ Xiaoman Liu $\left(\mathbb{D},{ }^{1}\right.$ \\ and Zhigang Niu ${ }^{4}$ \\ ${ }^{1}$ School of Resource and Environment, Henan Polytechnic University, Jiaozuo 454000, China \\ ${ }^{2}$ Collaborative Innovation Center of Coalbed Methane and Shale Gas for Central Plains Economic Region of Henan Province, \\ Jiaozuo 454000, China \\ ${ }^{3}$ State Collaborative Innovation Center of Coal Work Safety and Clean-Efficiency Utilization, Jiaozuo 454000, China \\ ${ }^{4}$ Henan Provincial Coal Geological Survey and Research Institute, Zhengzhou 450052, China
}

Correspondence should be addressed to Xinyi Wang; chenyun101205@outlook.com and Yanqi Zhao; zhaoyq@hpu.edu.cn

Received 25 May 2020; Revised 7 September 2020; Accepted 19 October 2020; Published 9 November 2020

Academic Editor: Hualei Zhang

Copyright $\odot 2020$ Yun Chen et al. This is an open access article distributed under the Creative Commons Attribution License, which permits unrestricted use, distribution, and reproduction in any medium, provided the original work is properly cited.

Taking the Suiqi coalfield located in North China as the object, where the coal seam burial depth is more than $1100 \mathrm{~m}$, the water abundance of the roof pore thermal storage aquifer is better than average, the ground temperature is abnormally high, and hydrogeological data are relatively lacking, this paper selects and determines eight index factors that influence the mining of the coalfield. Based on the analytic hierarchy process (AHP), the index factor weight is defined, and then, the threat degree of the roof thermal storage aquifer to the coal mining is quantitatively evaluated and divided by using the fuzzy variable set theory. The evaluation results show that the threat degree of the roof in the eastern region is generally greater than that in the western region and that the closer it is to the coal seam outcrop line, the higher the threat degree is; near the boreholes, in the areas Qs1,Qs5, Qs8, Sx1, Tk5, Zc4, and Zc7, which are close to the hidden outcrop line of the coal seam, the classification characteristic value of the threat degree is greater than 3.5, which is in the high-threat zone for disasters caused by roof thermal storage aquifers during coal seam mining. The area above the medium-threat zone accounts for $71.82 \%$ of the total study area, indicating that deep coal mining is affected by multiple factors and that roof water and heat disasters are more likely to occur.

\section{Introduction}

In North China coalfields and southern Ordos Basin coalfields, minable coal seams are directly or indirectly covered by thermal storage aquifers of different thicknesses and coal seam mining operations face the serious threats of double roof water inrush and geothermal disasters. For example, the normal water inflow of a coal mine in the southern margin of the Ordos Basin reaches $106,520 \mathrm{~m}^{3} / \mathrm{d}$ and the water temperature at a depth of $700 \mathrm{~m}$ reaches $41^{\circ} \mathrm{C}$, which greatly affect the normal production of the coal mine. To ensure the safety of underground mining engineering, the threat degree of the roof thermal storage aquifer has become an urgent problem that needs to be solved in coal mine production through scientific evaluation.
Many scholars have carried out a series of research works on the problem of coal seam roof disasters. The theories and methods formed mainly include the "upper three zones" theory [1-3], the "key layer" theory [4], the "three maps-double prediction method" [5], the mathematical comprehensive evaluation method [6], and the numerical simulation method [7]. Among them, the "upper three zones" theory is the most widely used, and the corresponding empirical formula calculation guides the prediction, evaluation, and prevention of a coal seam roof water inrush $[8,9]$. In recent years, some scholars have used comprehensive methods to solve practical production problems. For example, Booth and Breuer and $\mathrm{Wu}$ et al. applied MODFLOW software to simulate the hydrological effects of shallow aquifers under the influence of long-wall mining, put forward the change rule of 

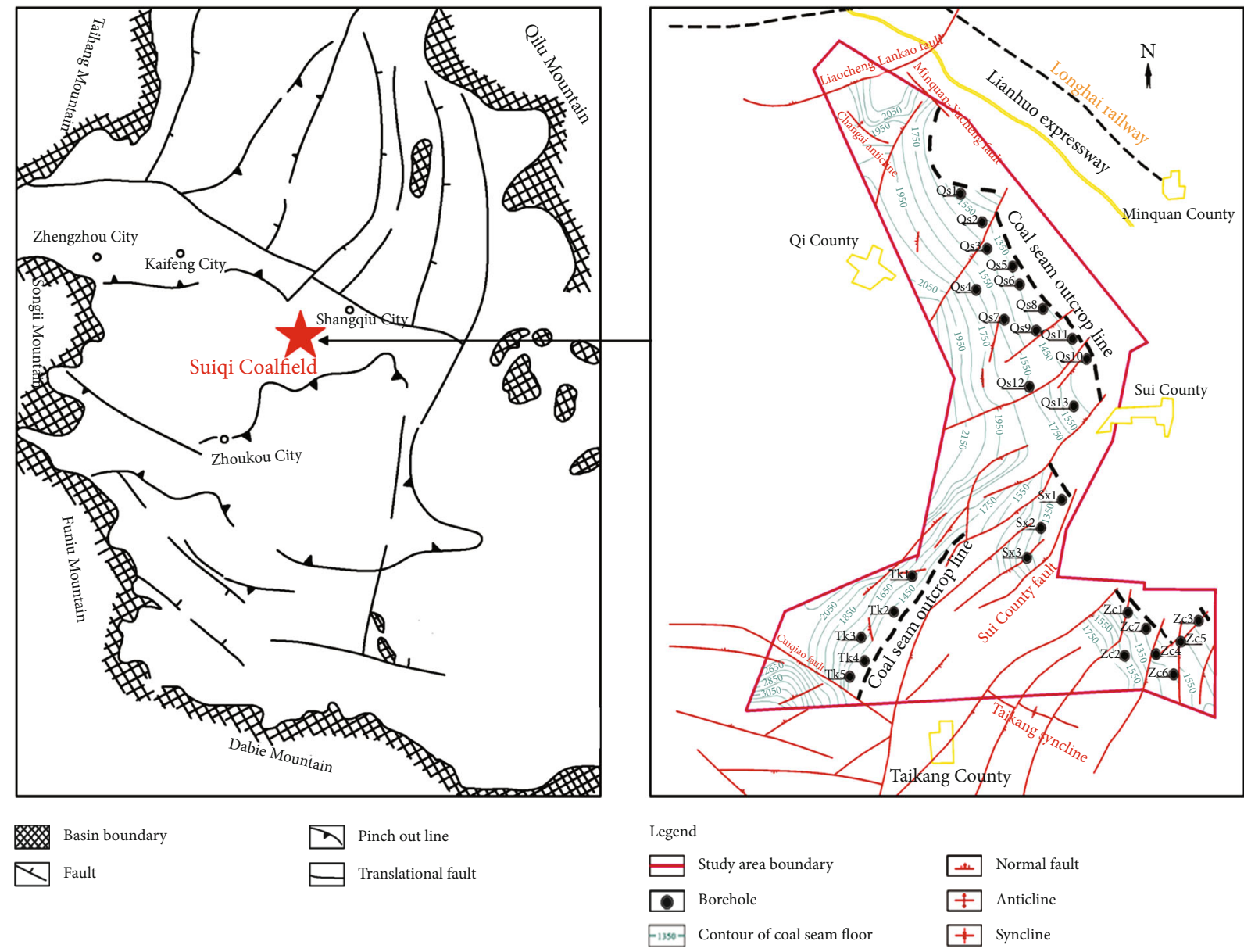

FIGURE 1: Schematic diagram of the location and geological structure of the Suiqi coalfield.

hydrological parameters, such as the water head with the mining time and space, and hypothesized that the cracks produced during mining caused the water head drop of the aquifer system [10, 11]. Zhou et al. established a conceptual model of mine water inrush composed of a core network, an underground monitoring network, and an operating system, and the underground excavation and water inrush disaster process can be simulated by using the raw underground data [12]. Zhang et al. obtained the height of the "upper three zones" by numerical simulation and used it to study the roof overburden failure [13]. Yang and Sun determined the height of the water flowing through the fractured zone by using a field measurement, numerical simulation, and empirical formulas in the "upper three zones" theory to reasonably determine the size of a waterproof safety coal pillar [14]. Yao et al. used numerical simulation software to simulate the distribution characteristics of the water flowing fracture zone and the seepage characteristics of the roof water during the mining of the workface; additionally, the water inrush risk of the roof aquifer was analyzed [15]. Based on the gray correlation analytic hierarchy process, Zhang and Yang proposed a prediction model for the roof water inrush when mining a shallow coal seam, and the model was verified with engineering examples [16]. Wu et al. and Zeng et al. studied the height of the water flowing fracture zone of the coal seam roof and the richness of the water-rich aquifer and then evaluated the water inrush risk of the aquifer according to the water-rich partition map $[17,18]$. Ren and $\mathrm{Wu}$ revised the "three figure double prediction method" and evaluated the risk of water inrush in the area where the height of the caving zone formed by coal mining is lower than the elevation of the roof aquifer [19]. Rezaei and Guo et al. used a neural network intelligent prediction model to determine the height of the water flowing fracture zone and evaluate the performance of the model by using a variety of performance indicators (correlation coefficients, variances, etc.) $[20,21]$. Ruan et al. proposed a prediction model for the water inrush based on the AHP and the DempsterShafer evidence theory, and the feasibility and applicability of the model were also verified [22].

Obviously, the above research results are mainly focused on the prediction and prevention of roof water disasters, while there are few studies on the evaluation of the threat degree of water hazard under the superimposed effect of high ground temperature. In addition, the existing methods needing to be improved generally predict the possibility of roof water inrush based on stratum lithology and mining influence, which fails to fully reflect the combined effects of multiple factors such as geology, hydrogeology, geothermal field, and mining failure. Therefore, it is of great significance to 


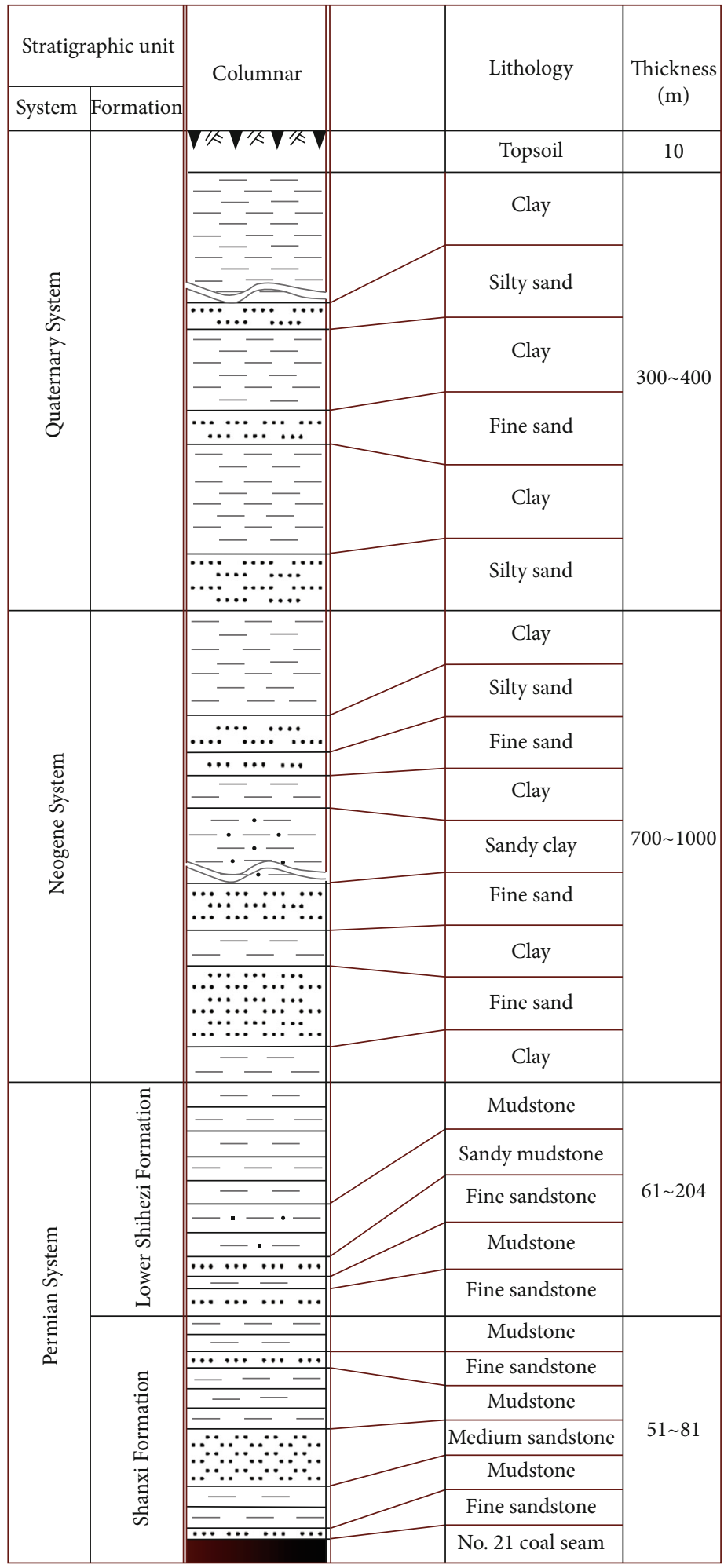

FIGURE 2: Combined geological column of the stratum.

carry out research on the threat degree of water-heat coupling disaster under deep coal mining conditions.

In this paper, taking the Suiqi coalfield located in the North China coalfield area as the object, based on the collected and measured geothermal well and exploration bore- hole data, the key evaluation indicators among factors such as the geology, hydrogeology, geothermal field, and mining failure were selected. Then, based on fractal theory, AHP, and fuzzy variable set theory, a mathematical model is constructed, by which the impact degree of the thermal storage 
TABLE 1: The main geological structures in the study area.

\begin{tabular}{|c|c|}
\hline Structure & Occurrence factors \\
\hline $\begin{array}{l}\text { Changsi } \\
\text { anticline }\end{array}$ & $\begin{array}{l}\text { The axial direction is NW, with a length of } \\
\text { approximately } 7 \mathrm{~km} \text {; the two wings are basically } \\
\text { symmetrical, and the inclination angles of the } \\
\text { two wings are approximately } 5^{\circ} \text {, which is a } \\
\text { wide and gentle anticline }\end{array}$ \\
\hline Taikang syncline & $\begin{array}{l}\text { The axial direction is NW, with a length of } \\
\text { approximately } 14 \mathrm{~km} \text {, and the inclination } \\
\text { angles of both wings are more than } 20^{\circ} \text {. It } \\
\text { is cut by a series of NE trending faults with } \\
\text { incomplete morphologies }\end{array}$ \\
\hline $\begin{array}{l}\text { Liaocheng- } \\
\text { Lankao fault }\end{array}$ & $\begin{array}{l}\text { Strike NE, dip NW, dip angle } 40 \sim 70^{\circ} \text {, } \\
\text { drop greater than } 900 \sim 4000 \mathrm{~m}\end{array}$ \\
\hline Suixian fault & $\begin{array}{l}\text { Strike NE, dip NW, dip angle } 60 \sim 70^{\circ} \text {, } \\
\text { drop greater than } 1000 \mathrm{~m} \text {, extension } \\
\text { length greater than } 30 \mathrm{~km}\end{array}$ \\
\hline $\begin{array}{l}\text { Minquan- } \\
\text { Yucheng fault }\end{array}$ & $\begin{array}{l}\text { Strike NW, dip NE, dip angle } 50 \sim 70^{\circ} \text {, } \\
\text { drop greater than } 1500 \mathrm{~m}\end{array}$ \\
\hline Cuiqiao fault & $\begin{array}{l}\text { Strike NW, dip SW, dip angle } 60 \sim 70^{\circ} \text {, } \\
\text { drop } 0-800 \mathrm{~m} \text {, extension length } 35 \mathrm{~km}\end{array}$ \\
\hline
\end{tabular}

aquifer on deep coal mining was quantitatively evaluated. The results can provide technical support for the layout of mining engineering and safety production under the cover of a thermal storage aquifer and can also provide a reference for the identification of roof water and heat disasters in other mining areas in the North China coalfield.

\section{Geological and Hydrogeological Characteristics}

The Suiqi coalfield (Figure 1), which encompasses an area of approximately $4900 \mathrm{~km}^{2}$, is located at the junction of Kaifeng City, Shangqiu City, and Zhoukou City in the central part of the North China coalfield area. At a burial depth of $1100 \sim 2000 \mathrm{~m}$ is the no. $2_{1}$ coal seam, whose average thickness and coal reserves are $5.3 \mathrm{~m}$ and 23 billion tons, respectively. With the gradual depletion of coal resources in other areas, to meet the needs of economic and social development, the mining of coal resources in this coalfield will be imperative.

2.1. Geological Characteristics. According to the drilling data, the strata overlying the no. $2_{1}$ coal seam in the coalfield area include the Shanxi Formation $\left(\mathrm{P}_{1} \mathrm{sh}\right)$ and the Lower Shihezi Formation $\left(\mathrm{P}_{1} \mathrm{x}\right)$ of the Permian System, the Neogene System $(\mathrm{N})$, and the Quaternary System $(\mathrm{Q})$. The combined geological column of the stratum can be seen in Figure 2.

The geological structure in this area is relatively developed (Figure 1), with Changsi anticline in the north and Taikang syncline in the south. The faults mainly include the Liaocheng-Lankao fault, Suixian fault, Minquan-Yucheng fault, Cuiqiao fault, and other high-angle normal faults. The faults have large drops and extensions, and the occurrence factors are shown in Table 1. These geological structures have destroyed the occurrence of coal seams at different degrees, leading to a lack of coal-bearing strata and changes in the coal thickness.
2.2. Hydrogeological Characteristics. The roof aquifers affect the excavation of the no. $2_{1}$ coal seam of the sandstone fracture aquifer group of the Shanxi Formation and Lower Shihezi Formation and the pore aquifer group of the Neogene period. The water richness of the sandstone fissure aquifer group in the Shanxi Formation and the Xiashihezi Formation is relatively weak, and it has little effect on the mining of the no. $2_{1}$ coal seam in the case of no supply source.

The Neogene aquifer group is mainly composed of a fine sand medium that has good water richness with an average unit water inflow of $0.73 \mathrm{~L} /(\mathrm{s} \cdot \mathrm{m})$. The aquifer group directly affects the mining of the no. $2_{1}$ coal seam in the hidden outcrop area of the coal seam and indirectly threatens the mining of the no. $2_{1}$ coal seam in other areas through the underlying aquifer group.

The geothermal gradient in this area is between 3.35 and $3.81^{\circ} \mathrm{C} / 100 \mathrm{~m}$, with an average value of $3.58^{\circ} \mathrm{C} / 100 \mathrm{~m}$. The average temperature of the surrounding rock and groundwater at a depth of $1100 \mathrm{~m}$ can reach $54.56^{\circ} \mathrm{C}$. The coal mining operations will be affected by abnormally high geothermal disasters.

\section{Index Factor Selection and Weight Determination}

3.1. Index Factor Selection. The threat degree of the roof thermal storage aquifer during mining in the Suiqi coalfield is mainly controlled by the geological, hydrogeological, and geothermal fields; mining failure; and other factors (as shown in Figure 3).

The geological factors include the overburden structure of the coal seam, the rock thickness, the burial depth of the coal seam roof, and the fault characteristics. The roof of the no. $2_{1}$ coal seam in the coalfield area is an interlayer of brittle sandstone and plastic mudstone. The greater the number of sandstone layers and the greater the thickness of a single layer, the more easily the roof will be damaged under the influence of mining. Therefore, the thickness ratio of the brittle and plastic rock (the ratio of brittle rock thickness to plastic rock thickness) exposed by drilling can be used to characterize the structure and thickness of the coal seam overburden. The deeper the burial depth of the coal seam roof and the thicker the overlying rock layer, the greater the pressure on the roof will be during mining. The more complex the faults of the coal seam roof are, the higher the roof failure height is and the greater the water inrush is. Therefore, the thickness ratio of the brittle and plastic rock, the burial depth of the coal seam roof, and the fault complexity are chosen to reflect the influence of the geological factors in this paper.

The hydrogeological factors include the thickness of the aquifer and the water richness within the height of the "upper three zones" of a roof failure. The greater the thickness and the stronger the water richness, the more water that is provided during the inrush it has and the more harmful it is. The thickness of the aquifer and water richness can be obtained from the drilling and field pumping (injection) water test data. Because the Suiqi coalfield is in the exploration stage, no pumping (injection) water test has been carried 


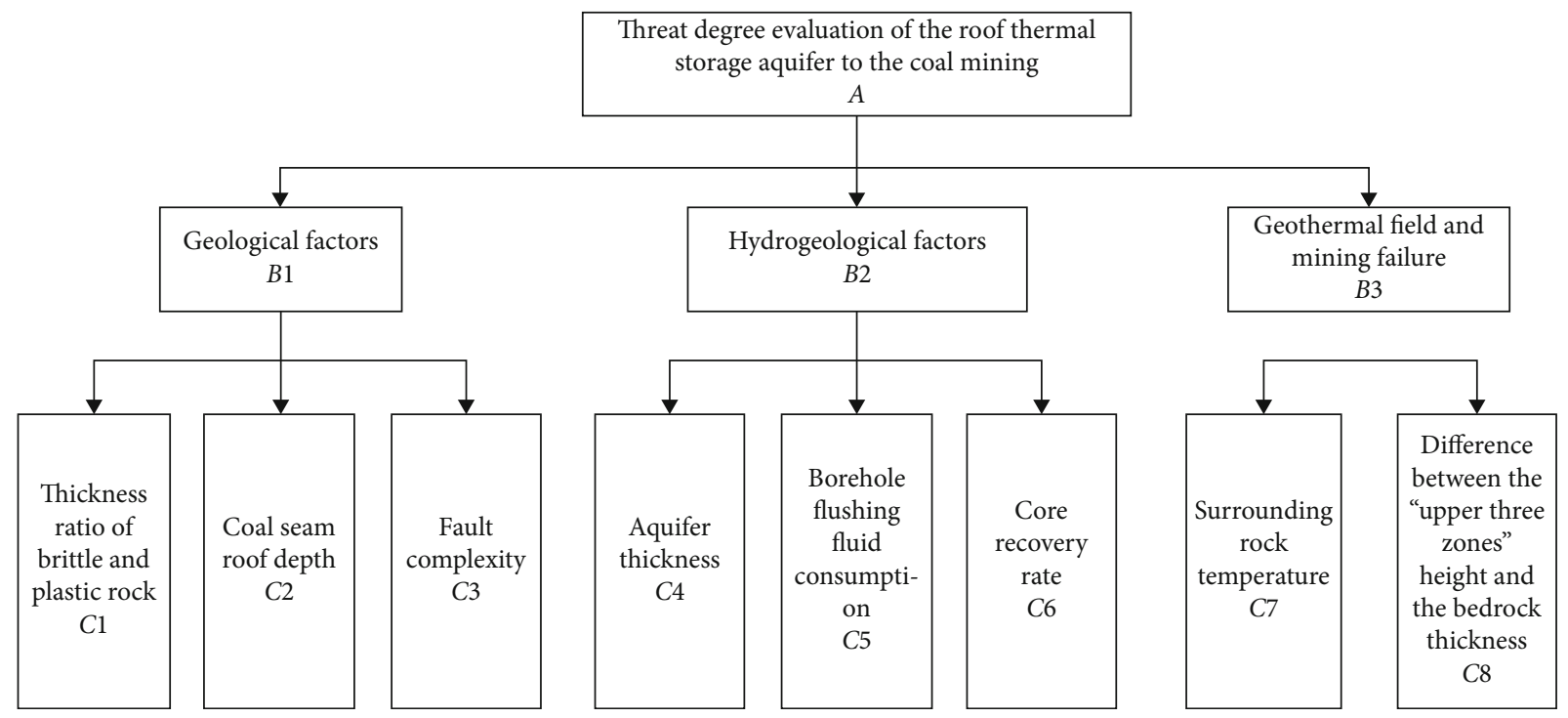

Figure 3: Evaluation index factors of the threat degree during deep coal mining.

TABLE 2: Judgment matrix $A-B_{i}(i=1,2,3)$.

\begin{tabular}{ccccc}
\hline$A$ & $B_{1}$ & $B_{2}$ & $B_{3}$ & $w\left(A / B_{i}\right)$ \\
\hline$B_{1}$ & 1 & $8 / 9$ & $7 / 9$ & 0.2925 \\
$B_{2}$ & $9 / 8$ & 1 & $9 / 7$ & 0.3164 \\
$B_{3}$ & $9 / 7$ & $9 / 7$ & 1 & 0.3911 \\
\hline
\end{tabular}

Note: maximum characteristic value $\lambda_{\max }=3.0016, \mathrm{CI}=0.0008<0.1$, and $\mathrm{CR}=0.0014<0.1$.

TABLe 3: Judgment matrix $B_{1}-C_{i}(i=1,2,3)$.

\begin{tabular}{ccccc}
\hline$B_{1}$ & $C_{1}$ & $C_{2}$ & $C_{3}$ & $w\left(B_{1} / C_{i}\right)$ \\
\hline$C_{1}$ & 1 & $4 / 3$ & $1 / 6$ & 0.1443 \\
$C_{2}$ & $3 / 4$ & 1 & $1 / 5$ & 0.1265 \\
$C_{3}$ & 6 & 5 & 1 & 0.7285 \\
\hline
\end{tabular}

Note: maximum characteristic value $\lambda_{\max }=3.0247, \mathrm{CI}=0.0124<0.1$, and $\mathrm{CR}=0.0213<0.1$.

out at present. In addition, the number of geothermal wells constructed in the area is limited, and it is difficult to obtain the unit water inflow, which characterizes the water richness of the aquifer. In the absence of the unit water inflow, the drill flushing fluid consumption and core recovery rate can be used as a substitute measure $[23,24]$. The greater the consumption of flushing fluid during drilling construction, the more developed the pores and cracks in the rock layer are and the stronger the water richness of the aquifer is.

The ground temperature of the Suiqi coalfield is abnormally high. To directly show the threat of the ground temperature field to deep coal seam mining, the surrounding rock temperature at the depth of the coal seam roof is used to indicate its influence. In the Suiqi coalfield, the bedrock composed of sandstone and mudstone is separated between the Neogene thermal reservoir aquifer group and the no. $2_{1}$ coal seam to be mined. The larger the difference between roof failure height and the whole thickness of the bedrock during coal
Table 4: Judgment matrix $B_{2}-C_{i}(i=1,2,3)$.

\begin{tabular}{ccccc}
\hline$B_{2}$ & $C_{4}$ & $C_{5}$ & $C_{6}$ & $w\left(B_{2} / C_{i}\right)$ \\
\hline$C_{4}$ & 1 & $6 / 5$ & $3 / 2$ & 0.4000 \\
$C_{5}$ & $5 / 6$ & 1 & $5 / 4$ & 0.3333 \\
$C_{6}$ & $2 / 3$ & $4 / 5$ & 1 & 0.2667 \\
\hline
\end{tabular}

Note: maximum characteristic 5value $\lambda_{\max }=3, \mathrm{CI}=0<0.1$, and $\mathrm{CR}=0<$ 0.1 .

TABle 5: Judgment matrix $B_{3}-C_{i}(i=1,2)$.

\begin{tabular}{lccc}
\hline$B_{3}$ & $C_{7}$ & $C_{8}$ & $w\left(B_{3} / C_{i}\right)$ \\
\hline$C_{7}$ & 1 & $1 / 3$ & 0.2500 \\
$C_{8}$ & 3 & 1 & 0.7500 \\
\hline Note: maximum & &
\end{tabular}

mining, the higher the influence of the Neogene thermal storage aquifer is on the coal seam mining. Therefore, the difference between height of the "upper three zones" and the bedrock thickness is chosen to characterize the impact of a mining failure.

In short, it is reasonable and practical to select the following eight elements as index factors to evaluate the threat degree of the overlying thermal aquifer during coal mining operations: the thickness ratio of brittle and plastic rock, the coal seam roof depth, the fault complexity, the aquifer thickness, the borehole flushing fluid consumption, the core recovery rate, the surrounding rock temperature, and the difference between the height of the "upper three zones" and the bedrock thickness.

According to the water and heat disaster characteristics of a coal seam roof [1], the difference between the height of the "upper three zones" and the bedrock thickness and the complexity of the fault should be the most important levels among the eight index factors; the aquifer thickness, borehole flushing fluid consumption, core recovery rate, 
TABLE 6: Weights of the evaluation index factors.

\begin{tabular}{lcccccccc}
\hline Index factor & $C_{1}$ & $C_{2}(\mathrm{~m})$ & $C_{3}$ & $C_{4}(\mathrm{~m})$ & $C_{5}\left(\mathrm{~m}^{3} / \mathrm{h}\right)$ & $C_{6}$ & $C_{7}\left({ }^{\circ} \mathrm{C}\right)$ & $C_{8}$ \\
\hline Weight & 0.0422 & 0.0370 & 0.2131 & 0.1267 & 0.1055 & 0.0844 & 0.0978 & 0.2933 \\
\hline
\end{tabular}

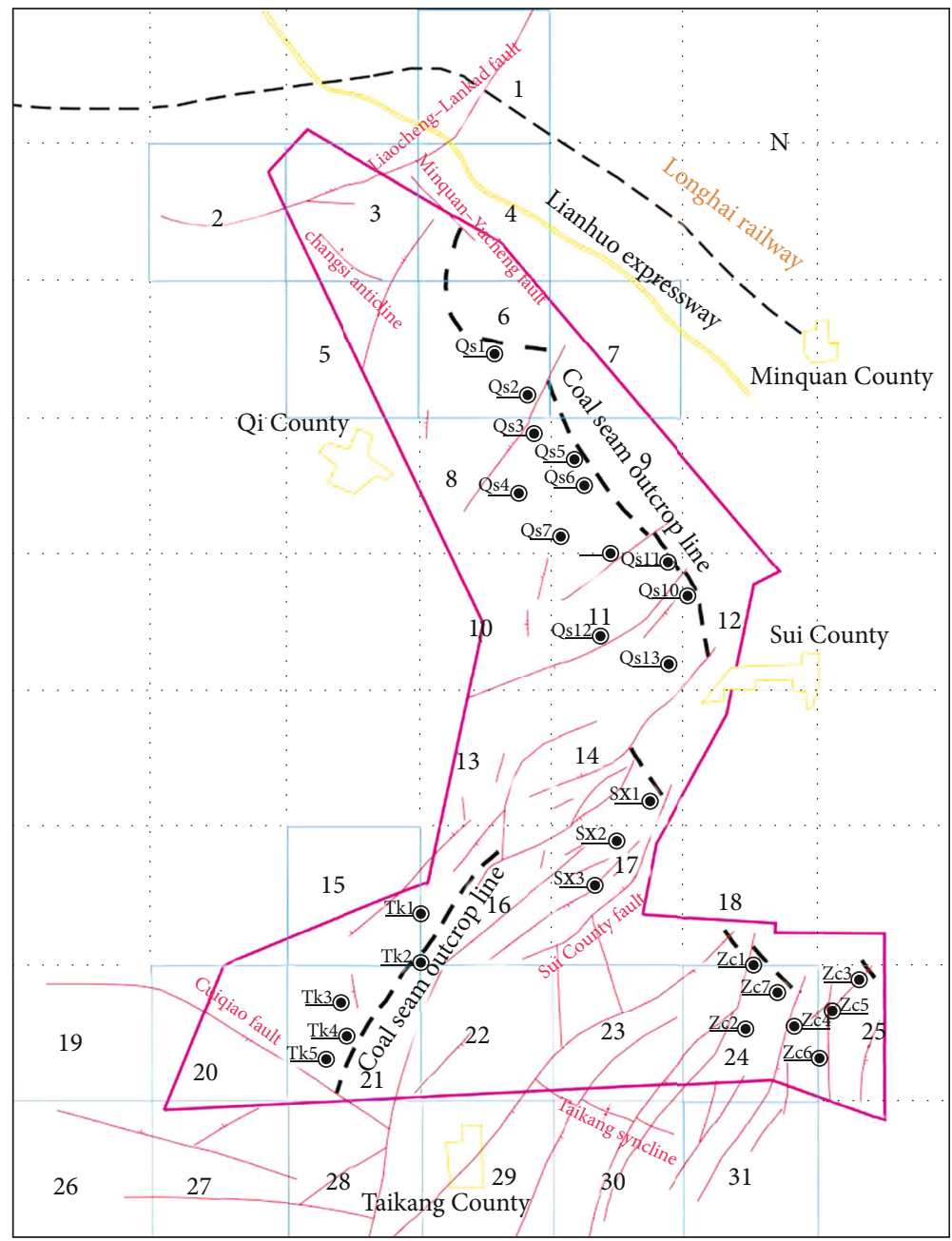

Legend

$\square$ Study area boundary

Anticline

Normal fault

Syncline

Figure 4: Block number of the study area.

and surrounding rock temperature should be at the second most important influence level, while the coal seam roof depth and thickness ratio of brittle and plastic rock have been reflected in other indexes to some extent, and they should be at the third influence level.

3.2. Index Factor Weight. Referring to the existing results [25], the weights of the eight index factors can be determined by AHP. The judgment matrix of the evaluation system composed of the eight index factors is shown in Tables 2-5.

When the AHP model is used to determine the index factor weights, only when it is established that the consistency index $\mathrm{CI}<0.1$ and the consistency ratio $\mathrm{CR}<0.1$ can the judgment matrix and the single order of the factors be logically consistent and can the calculation results be credible. Obviously, the results of all the levels in this paper have passed the consistency test, and the determined index factor weights are credible. The results are shown in Table 6.

\section{Quantitative Value of Index Factors Divided}

4.1. Fault Complexity. The fractal theory can be used to distinguish the complexity of the faults in the study area [26]. According to a certain scale, the study area is into several square blocks, and the blocks containing faults are counted and numbered. For block $i$, first divide it according to the 
TABLE 7: Fractal dimension and correlation coefficient of each block.

\begin{tabular}{lccccc}
\hline Block number & Fractal dimension & Correlation coefficient & Block number & Fractal dimension & Correlation coefficient \\
\hline 1 & 1.2644 & 0.9893 & 17 & 1.5838 & 0.9981 \\
2 & 1.0247 & 0.9665 & 18 & 0.9007 & 0.9836 \\
3 & 1.1963 & 0.9879 & 19 & 1.3422 & 0.9730 \\
4 & 1.0095 & 0.9648 & 20 & 1.4700 & 0.9820 \\
5 & 1.0000 & 1.0000 & 21 & 1.3262 & 0.9705 \\
6 & 0.7551 & 0.9884 & 22 & 1.3415 & 0.9903 \\
7 & 0.6000 & 0.9000 & 23 & 1.5965 & 0.9823 \\
8 & 1.1755 & 0.9854 & 24 & 1.4548 & 0.9841 \\
9 & 0.9007 & 0.9836 & 25 & 1.4966 & 0.9853 \\
10 & 1.1288 & 0.9968 & 26 & 1.3136 & 0.9862 \\
11 & 1.4963 & 0.9721 & 28 & 1.5030 & 0.9809 \\
12 & 0.8340 & 0.9902 & 29 & 1.2943 & 0.9927 \\
13 & 1.2807 & 0.9661 & 30 & 1.4066 & 0.9713 \\
14 & 1.5975 & 0.9823 & 31 & 1.3222 & 0.9950 \\
16 & 1.0247 & 0.9665 & & 1.0703 & 0.9749 \\
\hline
\end{tabular}

TABLE 8: Fractal dimension values of the faults in the block where the borehole is located.

\begin{tabular}{lccccccc}
\hline $\begin{array}{l}\text { Borehole } \\
\text { number }\end{array}$ & $\begin{array}{c}\text { Fractal } \\
\text { dimension }\end{array}$ & $\begin{array}{c}\text { Drilling } \\
\text { number }\end{array}$ & $\begin{array}{c}\text { Fractal } \\
\text { dimension }\end{array}$ & $\begin{array}{c}\text { Drilling } \\
\text { number }\end{array}$ & $\begin{array}{c}\text { Fractal } \\
\text { dimension }\end{array}$ & $\begin{array}{c}\text { Drilling } \\
\text { number }\end{array}$ & $\begin{array}{c}\text { Fractal } \\
\text { dimension }\end{array}$ \\
\hline Qs1 & 0.7551 & Qs8 & 1.1755 & Sx2 & 1.5838 & Zc1 & 1.4548 \\
Qs2 & 0.7551 & Qs9 & 1.4963 & Sx3 & 1.5838 & Zc2 & 1.4548 \\
Qs3 & 1.1755 & Qs10 & 1.4963 & Tk1 & 1.0247 & Zc3 & Zc4 \\
Qs4 & 1.1755 & Qs11 & 1.4963 & Tk2 & 1.0247 & 1.4966 \\
Qs5 & 0.9007 & Qs12 & 1.4963 & Tk3 & 1.3262 & Zc5 & 1.4548 \\
Qs6 & 0.9007 & Qs13 & 1.4963 & Tk4 & 1.3262 & Zc6 & 1.4966 \\
Qs7 & 0.9007 & Sx1 & 1.5975 & Tk5 & 1.3262 & Zc7 & 1.4548 \\
\hline
\end{tabular}

TABLE 9: Height calculation formula for the "upper three zones".

\begin{tabular}{lccc}
\hline Code category & Overburden lithology & Formula 1 & Formula 2 \\
\hline Three lower code & Hard lithology & $H_{1}=\left(100 \sum M / 1.2 \sum M+2.0\right)+18.9$ & $H_{l}=30 \sqrt{\sum^{2}}+20$ \\
Medium hard lithology & $H_{l}=\left(100 \sum M / 1.6 \sum M+3.6\right)+15.6$ & $H_{l}=20 \sqrt{\sum_{M}+20}$ \\
Mining area code & Hard lithology & $H_{l}=\left(100 \sum M / 2.4 n+2.1\right)+21.2$ & - \\
& Medium hard lithology & $H_{l}=\left(100 \sum M / 3.3 n+3.8\right)+15.1$ & -
\end{tabular}

Note: $H_{l}$ is the height of the upper three zones (m), $M$ is the cumulative mining thickness (m) (when $M<6, n$ takes 1 ; when $M>6, n$ takes 2 ), and the bending zone height is taken as $10 \mathrm{~m}$ and is directly included in the formula.

magnification of scale $r=1 / 2$, and count the number of block segments containing fault trajectories $N(1 / 2)$; further, divide it according to the scale $r=1 / 4,1 / 8,1 / 16 \cdots$, and count the number of blocks $N(r)$ containing fault trajectories. Then, the fitting straight line equation of $\lg (r)$ and $\lg N(r)$ can be constructed, and the slope of the line is the fault fractal dimension $D$ of block $i$. In the same way, the fault fractal dimension of other blocks can be obtained. The larger the fractal dimension $D$, the more fault traces are contained in the block and the higher the complexity of the fault [27].

The study area is divided into 49 blocks, 31 of which are fault blocks, as shown in Figure 4. According to the above steps, the fractal dimension values of each block can be determined, and the results are shown in Table 7. Obviously, the fault fractal dimension range is $0.7551 \sim 1.5838$, with an average value of 1.2432. The correlation coefficients of $\lg (r)$ and 
TABLe 10: Difference between the height of the "upper three zones" and the bedrock thickness.

\begin{tabular}{lccccc}
\hline $\begin{array}{l}\text { Borehole } \\
\text { number }\end{array}$ & $\begin{array}{c}\text { Height of the } \\
\text { upper three zones" }\end{array}$ & $\begin{array}{c}\text { Difference between the height } \\
\text { of the "upper three zones" } \\
\text { and the bedrock thickness }\end{array}$ & $\begin{array}{c}\text { Borehole } \\
\text { number }\end{array}$ & $\begin{array}{c}\text { Height of the } \\
\text { "upper three zones" }\end{array}$ & $\begin{array}{c}\text { Difference between the height } \\
\text { of the "upper three zones" } \\
\text { and the bedrock thickness }\end{array}$ \\
\hline Qs1 & 93.27 & -39.73 & Sx2 & 122.79 & -143.21 \\
Qs2 & 84.25 & -235.14 & Sx3 & 93.47 & -156.05 \\
Qs3 & 139.20 & -87.75 & Tk1 & 103.27 & -187.55 \\
Qs4 & 76.06 & -263.67 & Tk2 & 49.46 & -70.98 \\
Qs5 & 77.64 & 15.20 & Tk3 & 97.70 & -204.17 \\
Qs6 & 93.87 & -32.37 & Tk4 & 165.11 & 103.46 \\
Qs7 & 121.20 & -193.92 & Tk5 & 160.77 & 77.64 \\
Qs8 & 118.30 & 21.58 & Zc2 & 91.45 & -37.45 \\
Qs9 & 96.93 & -69.22 & Zc3 & 40.87 & -175.14 \\
Qs10 & 48.07 & -62.10 & Zc4 & 111.87 & -94.38 \\
Qs11 & 81.42 & -73.09 & Zc5 & 131.20 & -35.52 \\
Qs12 & 76.83 & Zc6 & 120.76 & 81.17 \\
Qs13 & 73.85 & -146.91 & Zc7 & 93.18 & -33.32 \\
Sx1 & 97.92 & -212.14 & 3.81 & 23.15 \\
\hline
\end{tabular}

$\lg N(r)$ of each block are above 0.96 , which indicates that the fractal characteristics of the fault distribution in the study area are good under the selected scale. Additionally, the statistical self-similarity of the fractal structure is good, and the fractal dimension value can be used to represent the complexity of the fault.

The 28 geological boreholes belong to different blocks, and the fractal dimension representing the fault complexity is shown in Table 8 .

4.2. Difference between the Height of the "Upper Three Zones" and the Bedrock Thickness. After the coal seam is excavated, the roof overburden rock failure is divided into the collapse zone, crack zone, and bending zone (referred to as the "upper three zones"). According to the code for coal pillar reservation and mining under the pressure of buildings, water bodies, railways, and main shafts [28] (referred to as the "three lower code") and the code for hydrogeological engineering geological exploration in a mining area [29] (referred to as the "mining area code"), the height of the "upper three zones" can be calculated by using the empirical formula (Table 9). The maximum value is selected as the basic data for the evaluation in this paper [30] (see Table 10). The bedrock thickness of the coal seam roof can be determined by the drilling exploration results, and the difference between the height of the "upper three zones" and the bedrock thickness is shown in Table 10 .

4.3. Index Factor Set. The indexes, such as the thickness ratio of brittle and plastic rock, the aquifer thickness, the borehole flushing fluid consumption, the core recovery rate, the coal seam roof depth, and the surrounding rock temperature within the height of the "upper three zones" of roof failure, can be statistically obtained according to the actual information disclosed by the exploration drilling. For the conve- nience of evaluation, the reciprocal value of the core recovery rate is taken.

According to the 28 geological boreholes in the Suiqi coalfield, the quantitative values of the 8 index factors used to evaluate the threat degree of the thermal reservoir aquifer are listed in Table 11.

\section{Evaluation of the Impact Degree}

5.1. Basic Formula. Let $a, b, c, d$, and $k$ be the points on the fuzzy domain $U$ (see Figure 5), the interval $[a, b]$ belongs to the interval $[c, d]$, and the point $k$ is located at the midpoint of the interval $[a, b]$.

If the intervals $[a, b]$ and $[c, d]$ are denoted by $A$ and $B$, respectively, $u$ is any sample on $U$. According to the theory of fuzzy variable sets, the relative difference degree can be calculated as follows.

When $u$ is within interval $B$ and to the left of the $k$ point, then we have the following:

$$
\begin{cases}D_{A}(u)=\left(\frac{u-a}{k-a}\right)^{\beta}, & u \in[a, k], \\ D_{A}(u)=-\left(\frac{u-a}{c-a}\right)^{\beta}, & u \in[c, a] .\end{cases}
$$

When $u$ is within interval $B$ and to the right of the $k$ point, then we have the following:

$$
\begin{cases}D_{A}(u)=\left(\frac{u-b}{k-b}\right)^{\beta}, & u \in[k, b], \\ D_{A}(u)=-\left(\frac{u-b}{d-b}\right)^{\beta}, & u \in[b, d] .\end{cases}
$$


TABLE 11: Evaluation index value of the threat degree of the thermal storage aquifer.

\begin{tabular}{|c|c|c|c|c|c|c|c|c|}
\hline Borehole number & $C_{1}$ & $\mathrm{C}_{2}$ & $C_{3}$ & $\begin{array}{l}\text { Index } \\
C_{4}\end{array}$ & $C_{5}$ & $C_{6}$ & $C_{7}$ & $C_{8}$ \\
\hline Qs1 & 0.8224 & 1470.12 & 0.7551 & 42.09 & 1.9383 & 1.3966 & 56.18 & -39.73 \\
\hline Qs2 & 1.0064 & 1561.16 & 0.7551 & 42.26 & 0.0416 & 1.2005 & 58.68 & -235.14 \\
\hline Qs3 & 0.9559 & 1468.39 & 1.1755 & 62.57 & 0.2300 & 1.2092 & 56.13 & -87.75 \\
\hline Qs4 & 1.0053 & 1691.00 & 1.1755 & 38.65 & 0.0399 & 1.1338 & 62.25 & -263.67 \\
\hline Qs5 & 1.5949 & 1334.97 & 0.9007 & 47.72 & 3.1990 & 1.7212 & 52.46 & 15.20 \\
\hline Qs6 & 1.8727 & 1325.76 & 0.9007 & 32.11 & 0.0506 & 1.1038 & 52.21 & -32.37 \\
\hline Qs7 & 0.8099 & 1526.42 & 0.9007 & 48.42 & 0.0890 & 1.1792 & 57.73 & -193.92 \\
\hline Qs8 & 1.7077 & 1264.02 & 1.1755 & 59.43 & 2.9629 & 1.5949 & 50.51 & 21.58 \\
\hline Qs9 & 0.7841 & 1352.94 & 1.4963 & 42.60 & 1.8820 & 1.2690 & 52.96 & -69.22 \\
\hline Qs10 & 1.5810 & 1204.30 & 1.4963 & 27.51 & 0.7990 & 1.3986 & 48.87 & -62.10 \\
\hline Qs11 & 1.7095 & 1364.02 & 1.4963 & 51.37 & 0.2496 & 1.0834 & 53.26 & -73.09 \\
\hline Qs12 & 0.1789 & 1521.00 & 1.4963 & 11.66 & 0.9416 & 1.1601 & 57.58 & -146.91 \\
\hline Qs13 & 0.3719 & 1493.27 & 1.4963 & 20.14 & 0.1394 & 1.1403 & 56.81 & -212.14 \\
\hline Sx1 & 0.2864 & 1261.70 & 1.5975 & 17.85 & 2.1440 & 1.4327 & 47.59 & 3.81 \\
\hline $\mathrm{Sx} 2$ & 0.9584 & 1393.03 & 1.5838 & 39.16 & 1.6810 & 1.4085 & 50.90 & -143.21 \\
\hline Sx3 & 0.6118 & 1450.83 & 1.5838 & 30.39 & 0.0402 & 1.3850 & 52.36 & -156.05 \\
\hline Tk1 & 0.4415 & 1570.14 & 1.0247 & 29.82 & 0.1799 & 1.1173 & 64.51 & -187.55 \\
\hline Tk2 & 0.4131 & 1376.04 & 1.0247 & 14.46 & 0.0402 & 1.1390 & 58.47 & -70.98 \\
\hline Tk3 & 0.5381 & 1565.08 & 1.3262 & 24.13 & 0.0460 & 1.0905 & 64.35 & -204.17 \\
\hline Tk4 & 1.1794 & 1357.85 & 1.3262 & 29.80 & 2.9678 & 1.7301 & 57.91 & 103.46 \\
\hline Tk5 & 0.8309 & 1388.23 & 1.3262 & 45.42 & 2.8799 & 1.5748 & 58.85 & 77.64 \\
\hline $\mathrm{Zc1}$ & 0.4629 & 1277.50 & 1.4548 & 28.88 & 2.3816 & 1.8315 & 47.99 & -37.45 \\
\hline $\mathrm{Zc} 2$ & 0.9228 & 1460.61 & 1.4548 & 38.60 & 2.2623 & 1.6000 & 52.60 & -175.14 \\
\hline $\mathrm{Zc3}$ & 0.2077 & 1221.04 & 1.4966 & 4.31 & 0.3990 & 1.1274 & 46.57 & -94.38 \\
\hline $\mathrm{Zc4}$ & 1.5399 & 1339.83 & 1.4548 & 40.25 & 2.0805 & 1.9157 & 49.56 & -35.52 \\
\hline Zc5 & 1.4500 & 1202.78 & 1.4966 & 37.84 & 0.1294 & 1.1806 & 46.11 & 81.17 \\
\hline Zc6 & 2.2950 & 1318.17 & 1.4966 & 50.32 & 0.1218 & 1.2579 & 49.01 & -33.32 \\
\hline $\mathrm{Zc7}$ & 0.4280 & 1270.66 & 1.4548 & 39.88 & 2.6783 & 1.6026 & 47.82 & 23.15 \\
\hline Mean value $\rho$ & 0.9631 & 1393.9593 & 1.2972 & 35.6300 & 1.1641 & 1.3566 & 53.94 & -79.56 \\
\hline Standard deviation $\sigma$ & 0.5547 & 123.3001 & 0.2623 & 13.7339 & 1.1509 & 0.2446 & 5.17 & 98.33 \\
\hline
\end{tabular}

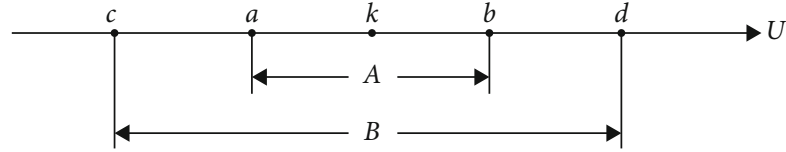

FIGURE 5: Schematic diagram of the location of the intervals $[a, b]$ and $[c, d]$.

When $u$ does not belong to interval $B$, then we have the following:

$$
D_{A}(u)=-1,
$$

where $\beta$ is an index greater than 0 , and usually $\beta=1$.

After using formulas (1)-(3) to obtain the relative difference degree $D_{A}(u)$, the following formula can be used to calculate the relative membership degree $\mu_{A}(u)$ :

$$
\mu_{A}(u)=\frac{1+D_{A}(u)}{2}
$$

If there are $n$ interval levels on the domain $U$ and the sample $u$ is composed of $m$ index factors, the comprehensive relative membership degree of the sample $u$ belonging to level $h$ can be calculated as follows:

$$
\varphi_{h}(u)=\left\{1+\left[\frac{\sum_{i=1}^{m}\left[w_{i}\left(1-\mu_{h}\left(\mu_{i}\right)\right)\right]^{p}}{\sum_{i=1}^{m}\left[w_{i} \mu_{h}\left(\mu_{i}\right)\right]^{p}}\right]^{\alpha / p}\right\}^{-1},
$$

where $\mu_{h}\left(u_{i}\right)$ is the relative membership of the index factor; $w_{i}$ is the weight of the index factor; $i=1,2$, $\cdots, m ; \quad h=1,2, \cdots, n ; \quad \alpha$ is the optimization criterion parameter $(\alpha=1$ or $\alpha=2)$; and $p$ is the distance parameter $(p=1$ is the Hamming distance and $p=2$ is the Euclidean distance). 
TABLE 12: Classification of the threat degree of the thermal reservoir aquifer.

\begin{tabular}{lccccc}
\hline Threat level & Safe (I) & Low threat (II) & Medium threat (III) & Relatively high threat (IV) & High threat (V) \\
\hline Level characteristic value & $H \leq 2.0$ & $2.0<H \leq 2.5$ & $2.5<H \leq 3.0$ & $3.0<H \leq 3.5$ & $H>3.5$ \\
\hline
\end{tabular}

TABLe 13: Calculation formula for the $[a, b]$ and $[c, d]$ assignment.

\begin{tabular}{lccccc}
\hline Threat level & Safe (I) & Low threat (II) & Medium threat (III) & Relatively high threat (IV) & High threat (V) \\
\hline$[a, b]$ & {$[\rho-1.25 \sigma, \rho-0.75 \sigma]$} & {$[\rho-0.75 \sigma, \rho-0.25 \sigma]$} & {$[\rho-0.25 \sigma, \rho+0.25 \sigma]$} & {$[\rho+0.25 \sigma, \rho+0.75 \sigma]$} & {$[\rho+0.75 \sigma, \rho+1.25 \sigma]$} \\
{$[c, d]$} & {$[\rho-1.5 \sigma, \rho-0.5 \sigma]$} & {$[\rho-\sigma, \mu]$} & {$[\rho-0.5 \sigma, \rho+0.5 \sigma]$} & {$[\rho, \rho+\sigma]$} & {$[\rho+0.5 \sigma, \rho+1.5 \sigma]$} \\
$k$ & $\rho-\sigma$ & $\rho-0.5 \sigma$ & $\rho$ & $\rho+0.5 \sigma$ & $\rho+\sigma$ \\
\hline
\end{tabular}

Note: $\rho$ and $\sigma$ are the mean and standard deviation of the index factor, respectively; when $a$ or $c$ is less than 0 , its value is 0 .

TABle 14: Composition of matrix $A B$.

\begin{tabular}{|c|c|c|c|c|c|}
\hline Index factor & Safe (I) & Low threat (II) & $\begin{array}{r}\text { Threat level } \\
\text { Medium threat (III) }\end{array}$ & Relatively high threat (IV) & High threat (V) \\
\hline$C_{1}$ & {$[0.27,0.55]$} & {$[0.55,0.82]$} & {$[0.82,1.10]$} & {$[1.10,1.38]$} & {$[1.38,1.66]$} \\
\hline$C_{2}$ & {$[1239.83,1301.48]$} & {$[1301.48,1363.13]$} & {$[1363.13,1424.78]$} & {$[1424.78,1486.43]$} & {$[1486.43,1548.08]$} \\
\hline$C_{3}$ & {$[0.97,1.10]$} & {$[1.10,1.23]$} & {$[1.23,1.36]$} & {$[1.36,1.49]$} & {$[1.49,1.63]$} \\
\hline$C_{4}$ & {$[18.46,25.33]$} & {$[25.33,32.20]$} & {$[32.20,39.06]$} & {$[39.06,45.93]$} & {$[45.93,52.80]$} \\
\hline$C_{5}$ & {$[0,0.30]$} & {$[0.3,0.88]$} & {$[0.88,1.45]$} & {$[1.45,2.03]$} & {$[2.03,2.60]$} \\
\hline$C_{6}$ & {$[1.05,1.17]$} & {$[1.17,1.30]$} & {$[1.30,1.42]$} & {$[1.42,1.54]$} & {$[1.54,1.66]$} \\
\hline$C_{7}$ & {$[47.48,50.06]$} & {$[50.06,52.65]$} & {$[52.65,55.23]$} & {$[55.23,57.82]$} & {$[57.82,60.40]$} \\
\hline$C_{8}$ & {$[-202.48,-153.31]$} & {$[-153.31,-104.15]$} & {$[-104.15,-54.98]$} & {$[-54.98,-5.81]$} & {$[-5.81,43.35]$} \\
\hline
\end{tabular}

TABle 15: Composition of matrix CD.

\begin{tabular}{|c|c|c|c|c|c|}
\hline Index factor & Safe (I) & Low threat (II) & $\begin{array}{l}\text { Threat level } \\
\text { Medium threat (III) }\end{array}$ & Relatively high threat (IV) & High threat $(\mathrm{V})$ \\
\hline$C_{1}$ & {$[0.13,0.69]$} & {$[0.41,0.96]$} & {$[0.69,1.24]$} & {$[0.96,1.52]$} & {$[1.24,1.80]$} \\
\hline$C_{2}$ & {$[1209.01,1332.31]$} & {$[1270.66,1393.96]$} & {$[1332.31,1455.61]$} & {$[1393.96,1517.26]$} & {$[1455.61,1578.91]$} \\
\hline$C_{3}$ & {$[0.90,1.17]$} & {$[1.03,1.30]$} & {$[1.17,1.43]$} & {$[1.30,1.56]$} & {$[1.43,1.69]$} \\
\hline$C_{4}$ & {$[15.03,28.76]$} & {$[21.90,35.63]$} & {$[28.76,42.50]$} & {$[35.63,49.36]$} & {$[42.50,56.23]$} \\
\hline$C_{5}$ & {$[0,0.59]$} & {$[0.01,1.16]$} & {$[0.59,1.74]$} & {$[1.16,2.32]$} & {$[1.74,2.89]$} \\
\hline$C_{6}$ & {$[0.99,1.23]$} & {$[1.11,1.36]$} & {$[1.23,1.48]$} & {$[1.36,1.60]$} & {$[1.48,1.72]$} \\
\hline$C_{7}$ & {$[46.19,51.36]$} & {$[48.77,53.94]$} & {$[51.36,56.52]$} & {$[53.94,59.11]$} & {$[56.52,61.69]$} \\
\hline$C_{8}$ & {$[-227.07,-128.73]$} & {$[-177.90,-79.56]$} & {$[-128.73,-30.4]$} & {$[-79.56,18.77]$} & {$[-30.4,67.94]$} \\
\hline
\end{tabular}

The calculation formula of the level characteristic value of sample $u$ is as follows:

$$
H(u)=\sum_{h=1}^{n} \frac{\varphi_{h}(u)}{\sum_{h=1}^{n} \varphi_{h}(u)} h
$$

According to the level characteristic value $H(u)$, the level of the sample $u$ can be judged.

5.2. Level Matrix Construction. In view of the fact that the overlying thermal storage aquifer in the study area has good water richness and is affected by a high ground temperature, referring to the existing research results [31], the threat degree of the overlying thermal storage aquifer of the coal seam is divided into five levels, i.e., safe, low threat, medium threat, relatively high threat, and high threat, which are expressed as I, II, III, IV, and V, respectively. The corresponding level characteristic values are shown in Table 12.

For a certain evaluation index factor, the intervals $[a, b]$ and $[c, d]$ corresponding to the five levels can be determined according to the mean-standard deviation method [32]. $k$ is the average value of $a$ and $b$, and the specific calculation formula is shown in Table 13. 
TABLE 16: Composition of matrix $K$.

\begin{tabular}{lccccc}
\hline $\begin{array}{l}\text { Index } \\
\text { factor }\end{array}$ & Safe (I) & $\begin{array}{c}\text { Low } \\
\text { threat (II) }\end{array}$ & $\begin{array}{c}\text { Medium } \\
\text { threat } \\
(\mathrm{III})\end{array}$ & $\begin{array}{c}\text { Relatively } \\
\text { high threat } \\
\text { (IV) }\end{array}$ & $\begin{array}{c}\text { High } \\
\text { threat } \\
(\mathrm{V})\end{array}$ \\
\hline$C_{1}$ & 0.4084 & 0.6858 & 0.9631 & 1.2405 & 1.5178 \\
$C_{2}$ & 1270.66 & 1332.31 & 1393.96 & 1455.61 & 1517.26 \\
$C_{3}$ & 1.0349 & 1.1661 & 1.2972 & 1.4284 & 1.5595 \\
$C_{4}$ & 21.8961 & 28.7631 & 35.6300 & 42.4970 & 49.3639 \\
$C_{5}$ & 0.0132 & 0.5887 & 1.1641 & 1.7396 & 2.3150 \\
$C_{6}$ & 1.1120 & 1.2343 & 1.3566 & 1.4789 & 1.6012 \\
$C_{7}$ & 48.7721 & 51.3561 & 53.9400 & 56.5240 & 59.1079 \\
$C_{8}$ & -177.8983 & -128.7312 & -79.5640 & -30.3969 & 18.7703 \\
\hline
\end{tabular}

TABLe 17: Relative difference matrix of borehole Qs1.

\begin{tabular}{lccccc}
\hline Index \\
factor & $\begin{array}{c}\text { Safe } \\
\text { (I) }\end{array}$ & $\begin{array}{c}\text { Low } \\
\text { threat } \\
(\mathrm{II})\end{array}$ & $\begin{array}{c}\text { Medium } \\
\text { threat (III) }\end{array}$ & $\begin{array}{c}\text { Relatively high } \\
\text { threat (IV) }\end{array}$ & $\begin{array}{c}\text { High } \\
\text { threat } \\
(\mathrm{V})\end{array}$ \\
\hline$C_{1}$ & -1 & -0.0171 & 0.0171 & -1 & -1 \\
$C_{2}$ & -1 & -1 & -1 & 0.5291 & -0.5292 \\
$C_{3}$ & -1 & -1 & -1 & -1 & -1 \\
$C_{4}$ & -1 & -1 & -0.8808 & 0.8821 & -1 \\
$C_{5}$ & -1 & -1 & -1 & 0.3162 & -0.3162 \\
$C_{6}$ & -1 & -1 & 0.39 & -0.39 & -1 \\
$C_{7}$ & -1 & -1 & -0.6218 & 0.6242 & -1 \\
$C_{8}$ & -1 & -0.5081 & -0.6204 & 0.6203 & -1 \\
\hline
\end{tabular}

TABLe 18: Relative membership matrix of borehole Qs1.

\begin{tabular}{|c|c|c|c|c|c|}
\hline \multirow[b]{2}{*}{$\begin{array}{l}\text { Index } \\
\text { factor }\end{array}$} & \multicolumn{5}{|c|}{ Threat level } \\
\hline & $\begin{array}{l}\text { Safe } \\
\text { (I) }\end{array}$ & $\begin{array}{l}\text { Low } \\
\text { threat } \\
\text { (II) }\end{array}$ & $\begin{array}{l}\text { Medium } \\
\text { threat (III) }\end{array}$ & $\begin{array}{l}\text { Relatively high } \\
\text { threat (IV) }\end{array}$ & $\begin{array}{c}\text { High } \\
\text { threat } \\
(\mathrm{V})\end{array}$ \\
\hline$C_{1}$ & 0 & 0.4914 & 0.5086 & 0 & 0 \\
\hline$C_{2}$ & 0 & 0 & 0 & 0.7646 & 0.2354 \\
\hline$C_{3}$ & 0 & 0 & 0 & 0 & 0 \\
\hline$C_{4}$ & 0 & 0 & 0.0596 & 0.9410 & 0 \\
\hline$C_{5}$ & 0 & 0 & 0 & 0.6581 & 0.3419 \\
\hline$C_{6}$ & 0 & 0 & 0.6950 & 0.3050 & 0 \\
\hline$C_{7}$ & 0 & 0 & 0.1891 & 0.8121 & 0 \\
\hline$C_{8}$ & 0 & 0 & 0.1899 & 0.8101 & 0 \\
\hline
\end{tabular}

According to the assignment criteria in Table 13, the $A B$, $C D$, and $K$ matrices are composed of the index factors and threat levels can be obtained, as shown in Tables 14-16.
TABLE 19: Comprehensive membership matrix of borehole Qs1.

\begin{tabular}{lccccc}
\hline $\begin{array}{l}\text { Parameter } \\
\text { assignment }\end{array}$ & $\begin{array}{c}\text { Safe } \\
\text { (I) }\end{array}$ & $\begin{array}{c}\text { Low } \\
\text { threat } \\
\text { (II) }\end{array}$ & $\begin{array}{c}\text { Medium } \\
\text { threat (III) }\end{array}$ & $\begin{array}{c}\text { Relatively } \\
\text { high threat } \\
\text { (IV) }\end{array}$ & $\begin{array}{c}\text { High } \\
\text { threat } \\
(\mathrm{V})\end{array}$ \\
\hline$\alpha=1, p=1$ & 0 & 0.0207 & 0.1618 & 0.5597 & 0.0448 \\
$\alpha=1, p=2$ & 0 & 0.0470 & 0.1892 & 0.5505 & 0.0822 \\
$\alpha=2, p=1$ & 0 & 0.0004 & 0.0359 & 0.6177 & 0.0022 \\
$\alpha=2, p=2$ & 0 & 0.0024 & 0.0516 & 0.6000 & 0.0080 \\
\hline
\end{tabular}

TABLE 20: Level characteristic values of borehole Qs1.

\begin{tabular}{lcccccc}
\hline & \multicolumn{6}{c}{ Threat level } \\
$\begin{array}{l}\text { Parameter } \\
\text { assignment }\end{array}$ & $\begin{array}{c}\text { Safe } \\
\text { (I) }\end{array}$ & $\begin{array}{c}\text { Low } \\
\text { threat } \\
\text { (II) }\end{array}$ & $\begin{array}{c}\text { Medium } \\
\text { threat } \\
\text { (III) }\end{array}$ & $\begin{array}{c}\text { Relatively } \\
\text { high threat } \\
\text { (IV) }\end{array}$ & $\begin{array}{c}\text { High } \\
\text { threat } \\
(\mathrm{V})\end{array}$ & Sum \\
\hline$\alpha=1, p=1$ & 0 & 0.0527 & 0.6169 & 2.8446 & 0.2845 & 3.7987 \\
$\alpha=1, p=2$ & 0 & 0.1081 & 0.6531 & 2.5344 & 0.4731 & 3.7685 \\
$\alpha=2, p=1$ & 0 & 0.0014 & 0.1643 & 3.7649 & 0.0167 & 3.9472 \\
$\begin{array}{l}\alpha=2, p=2 \\
\text { Mean }\end{array}$ & 0 & 0.0073 & 0.2339 & 3.6254 & 0.0601 & 3.9267 \\
value & 0 & 0.0424 & 0.4170 & 3.1933 & 0.2074 & 3.8603 \\
\hline
\end{tabular}

5.3. Evaluation Results. For the borehole Qs1, the relative difference degree and relative membership degree (as shown in Tables 17 and 18) can be obtained by using formulas (1)-(6); then, the comprehensive membership degree and level characteristic values (as shown in Tables 19 and 20) under different parameters $\alpha$ and $p$ can be further calculated. The calculation results show that the average level characteristic value of borehole Qs1 is 3.8603, which belongs to a highthreat area according to the classification standard in Table 12. According to the calculation steps of borehole Qs1, the level characteristic values of 28 boreholes can be given in turn, as shown in Table 21.

It can be seen from Table 21 that the proportion of the 28 boreholes that are in the high threat and relatively high threat levels is $57.14 \%, 32.14 \%$ of the boreholes are in the medium threat and low threat levels, and $10.71 \%$ of the boreholes are in the safe level.

Contour maps can be drawn based on the average level characteristic values of the 28 boreholes, and the threat degree division of the overlying thermal storage aquifer under the condition of coal mining can be delineated according to the criteria in Table 13, as shown in Figure 6.

The overall threat degree of the roof thermal storage aquifer is as follows: the threat degree in the western portion of the study area is less than that in the eastern portion, and the threat degree increases as the hidden outcrop line of the coal seam is approached. Due to the influences of multiple factors, the average level characteristic value $H$ of the areas near the boreholes Qs1,Qs5, Qs8, Sx1, Tk5, Zc4, and Zc7, 
TABLE 21: Borehole level characteristic value and threat degree level.

\begin{tabular}{|c|c|c|c|c|c|c|}
\hline $\begin{array}{l}\text { Borehole } \\
\text { number }\end{array}$ & $\begin{array}{l}\alpha=1, \\
p=1\end{array}$ & $\begin{array}{c}\text { Level ch } \\
\alpha=1, \\
p=2\end{array}$ & $\begin{array}{c}\text { aracteris } \\
\alpha=2, \\
p=1\end{array}$ & $\begin{array}{c}\text { tic value } \\
\begin{array}{c}\alpha=2 \\
p=2\end{array}\end{array}$ & $\begin{array}{l}\text { Mean } \\
\text { value }\end{array}$ & $\begin{array}{c}\text { Threat } \\
\text { degree level }\end{array}$ \\
\hline Qs1 & 3.7987 & 3.7685 & 3.9472 & 3.9267 & 3.8603 & $\mathrm{~V}$ \\
\hline Qs2 & 3.1859 & 3.1691 & 3.4444 & 3.4207 & 3.3050 & IV \\
\hline Qs3 & 2.5265 & 2.5628 & 2.4522 & 2.5588 & 2.5250 & III \\
\hline Qs4 & 2.2011 & 2.2613 & 2.0194 & 2.0668 & 2.1372 & II \\
\hline Qs5 & 4.2872 & 4.1676 & 4.8764 & 4.8075 & 4.5347 & $\mathrm{~V}$ \\
\hline Qs6 & 1.8210 & 1.8441 & 1.6587 & 1.6617 & 1.7464 & I \\
\hline Qs7 & 2.5865 & 2.6138 & 1.8951 & 1.8889 & 2.2461 & II \\
\hline Qs8 & 3.5078 & 3.4391 & 4.0806 & 3.9407 & 3.7421 & $\mathrm{~V}$ \\
\hline Qs9 & 3.4943 & 3.4589 & 3.5209 & 3.5204 & 3.4986 & IV \\
\hline Qs10 & 3.1276 & 3.1309 & 3.2121 & 3.2368 & 3.1768 & IV \\
\hline Qs11 & 3.2272 & 3.2326 & 3.3266 & 3.3260 & 3.2781 & IV \\
\hline Qs12 & 2.9278 & 2.8802 & 2.7781 & 2.6720 & 2.8145 & III \\
\hline Qs13 & 2.5854 & 2.9463 & 1.7968 & 2.5684 & 2.4742 & II \\
\hline Sx1 & 3.8993 & 3.9521 & 4.5876 & 4.6299 & 4.2672 & $\mathrm{~V}$ \\
\hline $\mathrm{Sx} 2$ & 3.0592 & 3.0541 & 2.9384 & 3.0072 & 3.0147 & IV \\
\hline $\mathrm{Sx} 3$ & 2.5640 & 2.7300 & 2.1946 & 2.5243 & 2.5032 & III \\
\hline Tk1 & 1.2672 & 1.3886 & 1.0412 & 1.0935 & 1.1976 & I \\
\hline Tk2 & 2.7366 & 2.9585 & 2.6189 & 2.9054 & 2.8048 & III \\
\hline Tk3 & 1.8434 & 2.1897 & 1.2607 & 1.7741 & 1.7670 & I \\
\hline Tk4 & 3.1855 & 3.1930 & 3.0486 & 2.9762 & 3.1008 & IV \\
\hline Tk5 & 3.9012 & 3.7841 & 3.9331 & 3.7070 & 3.8313 & $\mathrm{~V}$ \\
\hline $\mathrm{Zc1}$ & 3.3253 & 3.3231 & 3.6613 & 3.6741 & 3.4959 & IV \\
\hline $\mathrm{Zc} 2$ & 2.9098 & 2.7651 & 2.6888 & 2.2687 & 2.6581 & III \\
\hline $\mathrm{Zc3}$ & 2.7722 & 3.1029 & 2.5133 & 3.2040 & 2.8981 & III \\
\hline Zc4 & 3.7228 & 3.5441 & 3.9969 & 3.9215 & 3.7963 & $\mathrm{~V}$ \\
\hline Zc5 & 3.1836 & 3.1898 & 3.3773 & 3.4149 & 3.2914 & IV \\
\hline Zc6 & 3.3586 & 3.4039 & 3.3745 & 3.8063 & 3.4858 & IV \\
\hline $\mathrm{Zc7}$ & 3.8714 & 3.8507 & 4.4635 & 4.4201 & 4.1514 & $\mathrm{~V}$ \\
\hline
\end{tabular}

which are close to the hidden outcrop line of the coal seam, is greater than 3.5, which are the high-threat areas caused by the roof thermal storage aquifer.

According to the statistical results in Figure 6, it can be seen that the high-threat zone of the roof thermal storage aquifer accounts for $10.21 \%$ of the study area, the relatively high-threat zone accounts for $33.85 \%$, the medium-threat zone accounts for $27.76 \%$, the low-threat zone accounts for $19.76 \%$, and the safe zone accounts for $8.42 \%$. Obviously, the proportion of the area above the medium-threat zone is $71.82 \%$, and the possibility of a roof water and heat disaster accident occurring under coal mining conditions is greater.

5.4. Verification of Evaluation Results. According to the "upper three zones" theory of a coal seam roof, when the calculated height of the "upper three zones" is greater than the thickness of the bedrock, the roof failure zone of the coal mining operation will reach the overlying Neogene thermal storage aquifer with strong water richness and

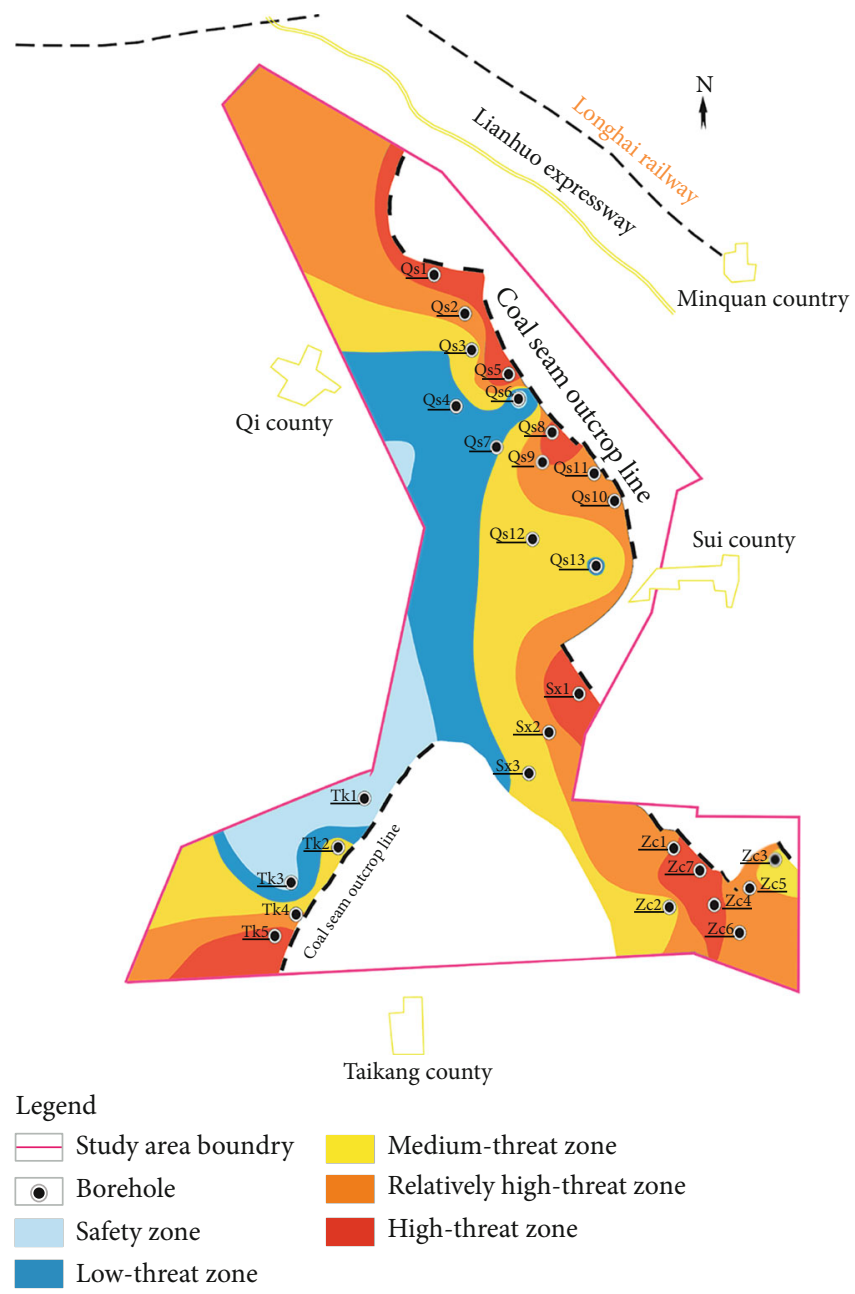

FIgURE 6: Threat degree division of the coal seam roof.

good permeability, which will greatly increase the risk of a roof disaster. Therefore, the difference between the thickness of the coal seam roof bedrock and the height of the "upper three zones" (referred to as "difference") is a common index and a traditional method to evaluate the roof threat level at present. The smaller the "difference" is, the greater the roof threat level is. The areas where the "difference" is negative belong to the high-threat areas of the roof.

The "difference" contour of the Suiqi coalfield is shown in Figure 7. Obviously, the "difference" in the west is larger than that in the east during the mining of the no. $2_{1}$ coal seam, which indicates that the roof disaster threat is greater as the hidden outcrop line of the coal seam is approached. In addition, the high-threat area of the roof in Figure 7 is located in the high-threat area and relatively high-threat area in Figure 6, which shows that the evaluation results of the "difference" method and the method adopted in this paper are basically the same. However, the fuzzy variable set method adopted in this paper considers more influencing factors and can obtain more precise evaluation results. 


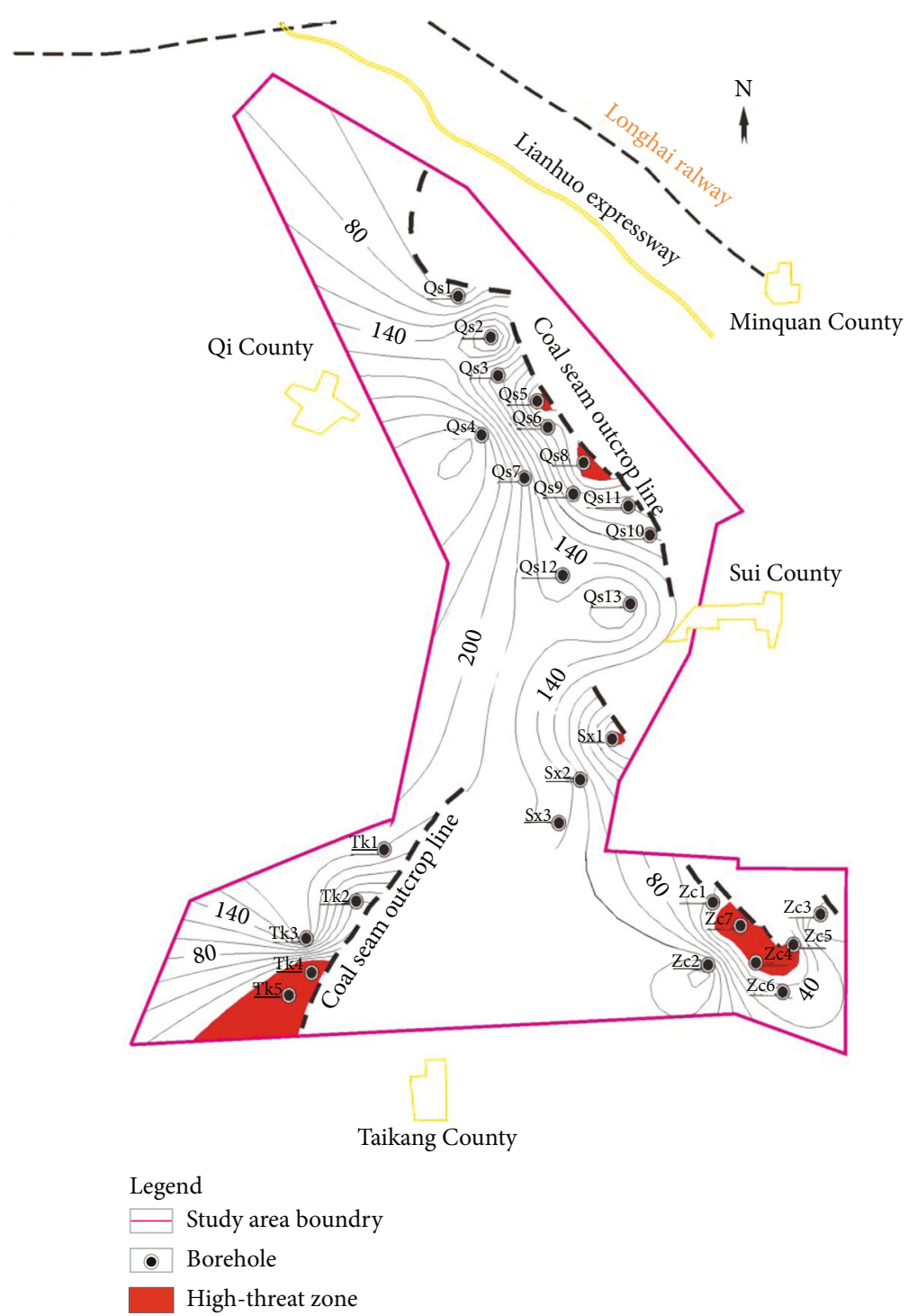

FIGURE 7: Difference contour diagrams between the thickness of the roof bedrock and the height of the "upper three zones."

\section{Conclusions}

(1) Based on the analysis of multiple factors affecting coal mining, eight factors are selected as the index factors for threat assessment, including the thickness ratio of brittle and plastic rock, the coal seam roof depth, the fault complexity, the aquifer thickness, the borehole flushing fluid consumption, the core recovery rate, the surrounding rock temperature, and the difference between the height of the "upper three zones" and the bedrock thickness, which provide a guarantee for the comprehensive and accurate identification of water and heat disasters of coal seam roofs

(2) The mathematical model of the threat degree evaluation is established by coupling the AHP and the fuzzy variable set theory. Based on the weights and quantitative values of the eight index factors, the threat degree of the thermal storage aquifer to the deep coal mining operation was identified and the threat degree was divided, which lays the foundation for the prevention and control of water and heat disasters of the overlying strata and safe mining

(3) The quantitative evaluation of the threat degree of the thermal storage aquifer shows that the risk in the western region is less than that in the eastern region, and the closer it is to the outcrop line of the coal seam, the greater the risk; in the areas near the boreholes Qs1,Qs5, Qs8, Sx1, Tk5, Zc4, and Zc7, which are close to the hidden outcrop line of the coal seam, the classification characteristic values of the threat degree are greater than 3.5, which belong to highthreat areas caused by the roof thermal storage aquifer. In these areas, roof water and heat disasters are prone to occur during coal mining

(4) According to the threat degree of the thermal storage aquifer of the coal seam roof, comparing the 
evaluation results of the traditional "upper three zones" theory (taking the difference between the thickness of the bedrock and the height of the "upper three zones" as parameters) with modern mathematical methods (coupling AHP and variable fuzzy set theory), it can be obtained that the evaluation results of the two methods are basically the same, but the evaluation results of the latter are more precise

(5) For the entire study area, the high-threat zone accounts for $10.21 \%$, the relatively high-threat zone accounts for $33.85 \%$, the medium-threat zone accounts for $27.76 \%$, the low-threat zone accounts for $19.76 \%$, and the safe zone accounts for $8.42 \%$. The area above the medium-threat zone accounts for $71.82 \%$, which includes a greater possibility of the roof water and a heat disaster occurring during mining of the no. $2_{1}$ coal seam

\section{Data Availability}

All data used to support the findings of this study are available from the corresponding author upon request.

\section{Conflicts of Interest}

The authors declare that they have no conflicts of interest.

\section{Acknowledgments}

This work was supported by the National Natural Science Foundation of China (Grant nos. 41672240 and 41972254), the Innovation Scientists and Technicians Troop Construction Projects of Henan Province (Grant no. CXTD2016053), and the Fundamental Research Funds for Henan Polytechnic University (NSFRF200103).

\section{References}

[1] M. G. Qian and T. C. Liu, Mine Pressure and Its Control, Coal Industry Press, Beijing, 1984.

[2] Q. D. Qu, J. L. Xu, R. L. Wu, W. Qin, and G. Z. Hu, "Threezone characterisation of coupled strata and gas behaviour in multi-seam mining," International Journal of Rock Mechanics and Mining Sciences, vol. 78, pp. 91-98, 2015.

[3] Z. P. Meng, X. C. Shi, and G. Q. Li, "Deformation, failure and permeability of coal-bearing strata during longwall mining," Engineering Geology, vol. 208, pp. 69-80, 2016.

[4] L. S. Jiang, Q. S. Wu, Q. L. Wu et al., "Fracture failure analysis of hard and thick key layer and its dynamic response characteristics," Engineering Failure Analysis, vol. 98, pp. 118-130, 2019.

[5] L. J. Zhai and C. X. Li, "Application of tri figure-double prediction methods in water disaster prevention and treatment evaluation of Pingshuo no. 3 mine shaft top roof," Procedia Earth and Planetary Science, vol. 3, pp. 470-476, 2011.

[6] A. J. Das, P. K. Mandal, S. P. Sahu, A. Kushwaha, R. Bhattacharjee, and S. Tewari, "Evaluation of the effect of fault on the stability of underground workings of coal mine through DEM and statistical analysis," Journal of the Geological Society of India, vol. 92, no. 6, pp. 732-742, 2018.
[7] Y. X. Zhang, S. H. Tu, Q. S. Bai, and J. J. Li, "Overburden fracture evolution laws and water-controlling technologies in mining very thick coal seam under water-rich roof," International Journal of Mining Science and Technology, vol. 23, no. 5, pp. 693-700, 2013.

[8] S. F. Wang, X. B. Li, and S. Y. Wang, "Separation and fracturing in overlying strata disturbed by longwall mining in a mineral deposit seam," Engineering Geology, vol. 226, pp. 257-266, 2017.

[9] K. F. Fan, W. P. Li, Q. Q. Wang et al., "Formation mechanism and prediction method of water inrush from separated layers within coal seam mining: a case study in the Shilawusu mining area, China," Engineering Failure Analysis, vol. 103, pp. 158172, 2019.

[10] C. J. Booth and E. P. Breuer, "Using MODFLOW with TMR to model hydrologic effects and recovery in the shallow aquifer system above longwall coal mining," in 10th InternationalMine-Water-Association Congress on Mine Water and the Environment, pp. 11-14, Karlovy Vary, Czech Republic, 2008.

[11] Q. Wu, Y. Z. Liu, L. H. Luo, S. Q. Liu, W. J. Sun, and Y. F. Zeng, "Quantitative evaluation and prediction of water inrush vulnerability from aquifers overlying coal seams in Donghuantuo coal mine, China," Environmental Earth Sciences, vol. 74, no. 2, pp. 1429-1437, 2015.

[12] Y. D. Zhou, Z. X. Li, C. P. Li, and Z. G. Cao, "Design and realization of mine water-inrush visualization simulation system," Advanced Materials Research, vol. 383-390, pp. 6632-6640, 2011.

[13] H. W. Zhang, Z. J. Zhu, L. J. Huo, Y. Chen, and B. J. Huo, "Overburden failure height of superhigh seam by fully mechanized caving method," Journal of China Coal Society, vol. 39, no. 5, pp. 816-821, 2014.

[14] Y. Yang and Q. F. Sun, "Two-band height observation of Gaotouyao coal mine 2-3 coal seam and safety mining under water," Safety in Coal Mines, vol. 46, no. 12, pp. 73-76, 2015.

[15] B. H. Yao, H. B. Bai, and B. Y. Zhang, "Numerical simulation on the risk of roof water inrush in Wuyang coal mine," International Journal of Mining Science and Technology, vol. 22, no. 2, pp. 273-277, 2012.

[16] J. Zhang and T. Yang, "Study of a roof water inrush prediction model in shallow seam mining based on an analytic hierarchy process using a grey relational analysis method," Arabian Journal of Geosciences, vol. 11, no. 7, 2018.

[17] Q. Wu, Y.Z. Liu, W. F. Zhou et al., "Evaluation of water inrush vulnerability from aquifers overlying coal seams in the Menkeqing coal mine, China," Mine Water and the Environment, vol. 34, no. 3, pp. 258-269, 2015.

[18] Y. F. Zeng, Q. Wu, S. Q. Liu, Y. L. Zhai, H. Q. Lian, and W. Zhang, "Evaluation of a coal seam roof water inrush: case study in the Wangiialing coal mine, China," Mine Water and the Environment, vol. 37, no. 1, pp. 174-184, 2018.

[19] X. B. Ren and R. F. Wu, "A modified three graphics-two predictions method based on hydraulic pressure of aquifers above coal seam roof," Coal Engineering, vol. 48, no. 11, pp. 131-133, 2016.

[20] M. Rezaei, "Development of an intelligent model to estimate the height of caving-fracturing zone over the longwall gobs," Neural Computing and Applications, vol. 30, no. 7, pp. 21452158, 2018.

[21] H. J. Guo, M. Ji, K. Chen, Z. L. Zhang, Y. D. Zhang, and M. L. Zhang, "The feasibility of mining under a water body based on a fuzzy neural network," Mine Water and the Environment, vol. 37, no. 4, pp. 703-712, 2018. 
[22] Z. Ruan, C. Li, A. Wu, and Y. Wang, “A new risk assessment model for underground mine water inrush based on AHP and D-S evidence theory," Mine Water and the Environment, vol. 38, no. 3, pp. 488-496, 2019.

[23] Z. L. Huo, "Field research on developing height of overlying strata overlying strata of thick layer fully-mechanized mining working face in Sihe mine," Morden Mining, vol. 12, pp. 711, 2012.

[24] G. Fang, "Risk evaluation of roof water inflow (inrush) and prevention and control measures in early mining areas of Balasu coal mine," Safety in Coal Mines, vol. 49, no. 12, pp. 189-193, 2018.

[25] F. Feng and L. He, "CBM block capacity potential partitioning based on AHP-a case study of coal no. 3 in Shizhuang north block, Shanxi," Coal Geology of China, vol. 30, no. 6, pp. 51$54,2018$.

[26] B. B. Mandelbrot, The Fractal Geometry of Nature (Updated and Augmented Edition), W. H. Freeman and Company, New York, 1983.

[27] R. Z. Li, Q. Wang, X. Y. Wang, X. Liu, J. Li, and Y. Zhang, "Relationship analysis of the degree of fault complexity and the water irruption rate, based on fractal theory," Mine Water and the Environment, vol. 36, no. 1, pp. 18-23, 2017.

[28] State Administration of Safety Supervision, Coal Pillar Reservation and Mining under Pressure of Buildings, Water bodies, Railways and Main shafts, China Standard Press, Beijing, 2017.

[29] State Bureau of Technical Supervision, "Hydrogeological engineering geological exploration in mining area," China Standard Press, Beijing, 1991.

[30] Y. C. Xu, J. C. Li, S. Q. Liu, and L. Zhou, "Calculation formula of two-zone height of overlying strata and its adaptability analysis," Coal mining Technology, vol. 16, no. 2, pp. 4-7, 2011.

[31] X. Y. Wang, Y. Zou, Q. Wang et al., "Quantitative evaluation of karst developmental differences based on improved analytic hierarchy process and multidimensional extension matter element model," Geofluids, vol. 2019, Article ID 5093237, 12 pages, 2019.

[32] S. Chen and T. Wang, "Comparison analyses of equal interval method and mean-standard deviation method used to delimitate urban heat island," Geo-information Science, vol. 11, no. 2, pp. 145-150, 2009. 